\title{
Ignorância e Políticas Públicas: a regulação de cannabis medicinal no Brasil ${ }^{1}$
}

Milena Karla Soares ${ }^{2}$

\section{INTRODUÇÃO}

Este artigo analisa as decisóes da Agência Nacional de Vigilância Sanitária (Anvisa) sobre regulação de cannabis para fins medicinais no Brasil no período de junho a dezembro de 2019, buscando identificar as implicações da ignorância ${ }^{3}$ (ou ausência de conhecimento) para a atuação da agência reguladora. Nesse período, a Anvisa deliberou simultaneamente sobre duas propostas de regulaçáo: a primeira sobre requisitos técnicos e administrativos para cultivo de cannabis para fins medicinais ou científicos e a segunda sobre o regulamento específico que flexibilizou as regras de registro de medicamentos à base de cannabis. Utilizou-se uma abordagem interpretativa para análise de conteúdo dos votos de membros da Diretoria Colegiada da Anvisa ao longo de processo deliberativo, que culminou com a rejeição e com o arquivamento da proposta de regulação do cultivo, concomitantemente à aprovação de regras mais flexíveis de registro de medicamentos à base de cannabis.

Espera-se que este artigo ofereça uma visão complementar aos demais que compóem esta edição do Boletim de Análise Politico-Institucional (Bapi), ao reconhecer que a ignorância pode ser um fator tão decisivo quanto o conhecimento nas políticas públicas. $\mathrm{O}$ texto está organizado em três seçôes, além desta introdução e da conclusão. Primeiramente, busca-se contextualizar as iniciativas de regulação da cannabis medicinal propostas pela Anvisa em 2019. Em seguida, apresenta-se uma revisão da literatura relativa a estudos sobre ignorância. Finalmente, apresenta-se a análise dos dados empíricos, estruturada em torno de seis principais "ignorâncias" mobilizadas nos votos, a saber: i) a cannabis apresenta propriedades terapêuticas?; ii) os produtos importados à base de cannabis apresentam segurança, eficácia e qualidade?; iii) a Anvisa tem competência para regular o plantio?; iv) a regulação do plantio reduzirá o custo dos medicamentos à base de cannabis?; $v$ ) quais serão os impactos da regulação do plantio em outros setores de políticas públicas?; e vi) há capacidade técnica e institucional dos órgáos governamentais envolvidos no controle e na fiscalização do plantio?

\section{CONTEXTO}

A cannabis foi "proibida" no Brasil em 1932, ${ }^{4}$ em decorrência de compromissos internacionais. Entretanto, ao contrário do senso comum, a proibição não é e nunca foi absoluta. O emprego para fins médicos, científicos e industriais permaneceu amparado pelo direito nacional e internacional. Trata-se do mesmo modelo aplicável a outras substâncias entorpecentes, a exemplo da papoula, planta

\footnotetext{
1. DOI: http://dx.doi.org/10.38116/bapi24art5

2. Técnica de desenvolvimento e administração na Diretoria de Estudos e Políticas do Estado, das Instituições e da Democracia (Diest) do Ipea. 3. A palavra ignorância é aqui entendida como um fenômeno social, ou seja, uma situação em que se percebe ou se alega ausência de conhecimento, e não como um atributo ou qualidade individual.

4. 0 Brasil aderiu à Convenção Internacional do Ópio de 1912. Em 1932, editou o Decreto nº 20.930/1932, que proibia diversas substâncias, cannabis inclusive. Atualmente, está em vigor a Lei no 11.343/2006. Quanto ao direito internacional, há três convenções vigentes: a Convenção Única sobre Entorpecentes de 1961, a Convenção sobre Substâncias Psicotrópicas de 1971 e a Convenção contra o Tráfico llícito de Entorpecentes e Substâncias Psicotrópicas de 1988.
} 
a partir da qual se produzem medicamentos - como morfina, codeína e diamorfina (heroína) - com aplicação médico-terapêutica, mas proscritos para uso recreativo.

Diferentemente da reconhecida utilidade terapêutica da papoula, a cannabis foi mantida à margem da pesquisa e do desenvolvimento farmacêutico. Em grande parte, isto se deve à temporalidade das descobertas científicas: no momento das primeiras negociaçôes internacionais sobre controle de drogas, o uso de medicamentos derivados da papoula já estava consolidado, mas pouco se sabia sobre o potencial da cannabis (Berridge, 2013). Em 1952, o comitê sobre drogas viciantes da Organização Mundial da Saúde (OMS) se posicionou dessa forma: "A questão da justificação do uso de preparaçóes de cannabis para propósitos medicinais foi discutida pelo comitê. Ele foi da opinião de que preparaçóes de cannabis são praticamente obsoletas. Até onde se pode ver, não há justificativa para uso médico de preparaçóes de cannabis" (OMS, 1952, tradução nossa). Essa declaração conferiu legitimidade científica ao regime de proibição da cannabis (Mills, 2012).

Nesse sentido, Nutt, King e Nichols (2013) argumentam que o regime de proibição dificulta a pesquisa devido ao aumento dos custos e tempos de licenciamento da autoridade responsável, exigência de controles policiais rigorosos e custosos, ausência ou baixa disponibilidade da substância, ofertada a preços proibitivos, além da falta de recursos pelo reduzido interesse de agências de financiamento no tema, bem como dificuldades para obter aprovação nos comitês de ética, em virtude do estigma associado à substância. Na prática, portanto, a proibição do uso recreativo tornou-se proibiçáo total, ao inibir pesquisa e desenvolvimento. Tal problemática não se restringe à cannabis, abarcando outras substâncias psicoativas proibidas, tais como a metilenodioximetanfetamina (MDMA), a psilocibina e a lysergsäurediethylamid (LSD), em relação aos quais há inúmeras questôes científicas não respondidas (Kempner, 2015; Nutt, King e Nichols, 2013).

Recentemente houve uma inflexão nesse cenário, devido ao ativismo de famílias de crianças com epilepsia de difícil controle que acreditam ter encontrado na cannabis um medicamento eficaz para o tratamento de convulsóes (Oliveira, 2016). O potencial terapêutico ganhou notoriedade em 2011, quando veio a público o caso da Charlotte Figi nos Estados Unidos. Sua mãe encontrou registros do uso de cannabis para tratamento de epilepsia remontando ao século XVIII, e passou a realizar experimentos, até encontrar a variedade que trouxesse o melhor resultado (McCall, 2015).

No Brasil, os pais de Anny Fischer foram os primeiros a conseguir na Justiça o direito de importar medicamento à base de cannabis, em abril de $2014,{ }^{5}$ e outros se seguiram. Diante da grande demanda proveniente de determinaçóes judiciais, bem como da pressão social relacionada ao ativismo de pacientes, a Anvisa passou a deliberar sobre o assunto. Em um primeiro momento, promovendo a reclassificação do canabidiol (CBD), ${ }^{6}$ de "proscrito" para "prescrito" e, na sequência, instituindo um regime simplificado de autorização excepcional das importações, em funcionamento desde 2015. O quadro 1 apresenta um resumo das principais resoluçóes da autoridade regulatória, entre 2015 e 2019.

5. Processo no 24632-22.2014.4.01.3400, da 3a Vara da Seção Judiciária do Distrito Federal, movido por Anny de Bortoli Fischer contra a Anvisa. 6. CBD e THC são substâncias presentes na planta cannabis. Ao contrário do THC, o CBD não possui propriedades psicoativas. 
QUADRO 1

Principais resoluções da Anvisa sobre a regulação da cannabis para uso medicinal (2015-2019)

\begin{tabular}{|c|c|c|}
\hline Assunto & $\begin{array}{l}\text { Reuniões ordinárias públicas (ROPs) ou Circuito } \\
\text { Deliberativo (CD) em que o tema foi debatido }\end{array}$ & $\begin{array}{l}\text { Resoluções da Diretoria } \\
\text { Colegiada (RDC) }\end{array}$ \\
\hline Reclassificação do CBD (de proscrito para prescrito) & $\begin{array}{l}\text { 9a ROP de 29/5/2014 (discutiu, mas não decidiu) 10 ROP } \\
\text { de 14/1/2015 (aprovou reclassificação) }\end{array}$ & RDC n- 3 de 26/1/2015 \\
\hline $\begin{array}{l}\text { Critérios e procedimentos para importação de produto à base } \\
\text { de CBD por pessoa física para uso próprio }\end{array}$ & $\begin{array}{l}\text { 1a ROP de 14/1/2015 (autorizou iniciativa)8a ROP de } \\
\text { 22/4/2015 (aprovou regulação) }\end{array}$ & RDC no 17 de 6/5/2015 \\
\hline $\begin{array}{l}\text { Excepcionar também o THC, }{ }^{1} \text { para cumprimento de decisão } \\
\text { judicial (Ação Civil Pública no 0090670-16.2014.4.01.3400) }\end{array}$ & CD 208 de 17/3/2016 (aprovou) & RDC no 66 de 18/3/2016 \\
\hline $\begin{array}{l}\text { Adequar a norma para viabilizar o registro do medicamento } \\
\text { Mevatyl }\end{array}$ & 27a ROP de 22/11/2016 (aprovou) & RDC no 130 de 2/12/2016 \\
\hline $\begin{array}{l}\text { Inclui cannabis na lista de "denominações comuns } \\
\text { brasileiras" }\end{array}$ & 9a ROP de 18/4/2017 (aprovou) & RDC no 156 de 5/5/2017 \\
\hline Simplificar o procedimento administrativo de importação & 21ㄴ ROP de 3/12/2019 (aprovou) & RDC n- 306 de 25/9/2019 \\
\hline $\begin{array}{l}\text { Requisitos técnicos e administrativos para o cultivo da } \\
\text { planta cannabis spp., exclusivamente para fins medicinais ou } \\
\text { científicos; e registro e monitoramento de medicamentos à } \\
\text { base de cannabis spp. }\end{array}$ & $\begin{array}{l}\text { 14a ROP de 11/6/2019 (aprovou realização de consultas } \\
\text { públicas)23a ROP de 15/10/2019 (discutiu, mas não } \\
\text { decidiu)29a ROP de 3/12/2019 (arquivou regulação } \\
\text { sobre cultivo e aprovou regulação sobre registro) }\end{array}$ & $\mathrm{RDC}$ n-327 de 9/12/2019 \\
\hline
\end{tabular}

Elaboração da autora.

Nota: ${ }^{\text {THC }}$ - Tetraidrocanabinol.

Nesse contexto e trajetória histórica recentes, inserem-se as deliberações objeto de análise neste artigo. Entre junho e dezembro de 2019, a Diretoria Colegiada da Anvisa tramitou simultaneamente duas propostas de regulaçáo: a primeira, sobre o plantio de cannabis para fins medicinais e científicos, que acabou sendo rejeitada e arquivada; e a segunda, sobre a flexibilização das regras para registro de medicamentos à base de cannabis, aprovada.

\section{REFERENCIAL TEÓRICO: IGNORÂNCIA E POLÍTICAS PÚBLICAS}

Neste artigo, busca-se lançar luz sobre o "reverso" do uso de evidências nas políticas públicas. Se evidência significa conhecimento, e o conhecimento humano é limitado, é de se esperar que existam situaçóes em que o conhecimento (ou evidência) necessário para a tomada de decisão simplesmente não esteja disponível: situaçôes de ignorância. Essas situações, em que o conhecimento é incompleto ou inconclusivo, são particularmente sensíveis ao tratar-se da atuação das agências reguladoras, cuja legitimidade, transparência e accountability fundamentam-se no conhecimento científico e na expertise técnica (Desmarais e Hird, 2014; Wagner, 2003).

De acordo com Smithson (2015), o campo de estudos sobre ignorância é multidisciplinar, sendo que recentemente tem havido um esforço de construção de um referencial que contemple as contribuiçóes teóricas e empíricas das diversas áreas (a exemplo de antropologia, sociologia, ciência política, filosofia, psicologia, economia comportamental, comunicaçáo, literatura e saúde e medicina).

Uma boa forma de começar a entender a ignorância é refletir sobre seus diversos tipos. Há diversas categorizaçóes propostas na literatura, ${ }^{7}$ cuja utilidade dependerá da finalidade analítica a que se destina. No quadro 2, apresenta-se uma tipologia adaptada de Roberts (2015) e Kerwin (1993). 
QUADRO 2

Tipologia da ignorância

\begin{tabular}{|c|c|c|}
\hline Origem da ignorância & Tipo de ignorância & Descrição \\
\hline \multirow{2}{*}{$\begin{array}{l}\text { Inexistência de } \\
\text { conhecimento }\end{array}$} & $\begin{array}{l}\text { Ignorância despercebida } \\
\text { (unknown unknown) }\end{array}$ & $\begin{array}{l}\text { Não há consciência sobre a existência da lacuna de conhecimento. Somente podemos mapear } \\
\text { esse tipo de ignorância em retrospecto, a partir do momento em que a ignorância é percebida } \\
\text { e muda de categoria (Roberts, 2015). }\end{array}$ \\
\hline & $\begin{array}{l}\text { Ignorância percebida } \\
\text { (known unknown) }\end{array}$ & $\begin{array}{l}\text { A lacuna de conhecimento é reconhecida e o conhecimento é inexistente no mundo. } \\
\text { Por exemplo, a existência de riscos, incertezas ou questões científicas não respondidas } \\
\text { (Kerwin, 1993; Roberts, 2015). }\end{array}$ \\
\hline \multirow{3}{*}{$\begin{array}{l}\text { Ignorância em relação a } \\
\text { conhecimento existente }\end{array}$} & $\begin{array}{l}\text { Ignorância percebida } \\
\text { e evitável }\end{array}$ & $\begin{array}{l}\text { Situações em que a lacuna de conhecimento é reconhecida e o conhecimento existe no } \\
\text { mundo. É possível superar essa ignorância, caso o agente queira, mas nem sempre o } \\
\text { esforço de obter o conhecimento vale a pena. Por exemplo, qualquer pessoa pode obter } \\
\text { conhecimentos jurídicos, mas em geral prefere-se contratar uma assessoria jurídica } \\
\text { (Roberts, 2015). }\end{array}$ \\
\hline & Conhecimento tácito & $\begin{array}{l}\text { O conhecimento não é articulado explicitamente, não há consciência sobre a sua existência. } \\
\text { Por exemplo, rotinas e práticas não sistematizadas (Kerwin, 1993; Roberts, 2015). }\end{array}$ \\
\hline & Erro & $\begin{array}{l}\text { Equívocos. Coisas que pensamos saber, mas não sabemos corretamente. Por exemplo, } \\
\text { conhecimento científico que acreditamos estar correto, mas que, em determinado momento, } \\
\text { prova-se falso, como a crença de que malária era causada pelo ar ruim (Kerwin, 1993), ou } \\
\text { ainda, um erro de dosagem na prescrição médica (Roberts, 2015). }\end{array}$ \\
\hline \multirow{4}{*}{$\begin{array}{l}\text { Ignorância pela } \\
\text { supressão de } \\
\text { conhecimento }\end{array}$} & Tabu & $\begin{array}{l}\text { Coisas que não devemos saber, mas que poderiam ser úteis se soubéssemos. Conhecimento } \\
\text { proibido ou perigoso (Kerwin, 1993). }\end{array}$ \\
\hline & Negação & $\begin{array}{l}\text { Coisas que são difíceis de aceitar, portanto escolhemos ignorar. Por exemplo, ignorar } \\
\text { evidências que coloquem dúvidas sobre a validade de crenças partilhadas unanimemente por } \\
\text { um grupo de pessoas (Roberts, 2015). }\end{array}$ \\
\hline & Segredo & $\begin{array}{l}\text { Conhecimento mantido oculto por motivos estratégicos, a exemplo dos segredos industriais } \\
\text { (Roberts, 2015). }\end{array}$ \\
\hline & Privacidade & $\begin{array}{l}\text { Conhecimento mantido oculto para proteger o direito à privacidade dos indivíduos, a exemplo } \\
\text { do sigilo das comunicações e contratações privadas (Roberts, 2015). }\end{array}$ \\
\hline
\end{tabular}

Elaboração da autora.

Ignorância e conhecimento são estágios entrelaçados no processo de compreensão do mundo, embora haja uma tendência humana de sobrevalorizar o que conhecemos e desprezar o que não conhecemos - e as razóes para não conhecermos (Kerwin, 1993). Se, por um lado, a consciência da ignorância funciona como um propulsor de novos conhecimentos, por outro, áreas de ignorância podem existir por fatores estruturais (históricos, culturais, sociais e políticos), ou ainda, atores podem fazer uso estratégico da ignorância para promover interesses, bem como manter ou subverter o ordenamento sociopolítico (McGoey, 2012). Nesse sentido, Schiebinger (2005, p. 320, tradução nossa) argumenta que "o que sabemos ou não sabemos, em determinado tempo ou local, é moldado pelas histórias particulares, prioridades globais ou locais, padróes de financiamento, hierarquias institucionais e disciplinares, miopia pessoal e profissional, e muito mais". É importante ressaltar, entretanto, que os usos da ignorância não são sempre perversos, existindo usos "virtuosos" relacionados, por exemplo, à proteção da privacidade e a princípios éticos (Smithson, 2015).

$\mathrm{Na}$ literatura de estudos sobre ignorância, convencionou-se chamar de "agnotologia" a área de estudo sobre a construção social da ignorância, seja passivamente, por fatores estruturais, ou ativamente, pela mobilização estratégica (Pinto, 2015). Nessa linha, Schiebinger (2005) investigou a produção cultural de ignorância no século XVIII, contexto da descoberta e colonização do "novo mundo", demonstrando que as propriedades abortíferas da planta poinciana pulcherrima L., utilizada 
pelos povos africanos escravizados das ilhas do Caribe, foram solenemente ignoradas nos catálogos de botânica europeia, apesar do ávido interesse dos exploradores em catalogar plantas e animais exóticos. A autora argumenta que o "esquecimento" desse conhecimento tradicional se deve a fatores políticos, pois "em uma economia em que produtores buscavam criar 'negros' como cavalos e gado, a recusa em procriar tornou-se um ato político" (Schiebinger, 2005, p. 329, traduçáo nossa). De modo semelhante, Kempner (2015) conceitua "conhecimento proibido", qual seja, conhecimento sensível, perigoso ou tabu, não produzido ou pouco pesquisado, embora relacionado à ignorância percebida. A não produção do conhecimento está relacionada a questóes metodológicas e éticas ou às consequências do conhecimento como ameaça à ordem sagrada natural ou à ordem social. Adicionalmente, Hess (2015) discute o conceito de "ciência inacabada" para referir-se a uma situação em que a inexistência do conhecimento resulta do exercício de poder por elites políticas e industriais, em detrimento de grupos menos favorecidos da sociedade aos quais faltam os recursos (financeiros e políticos) necessários para conduzir pesquisas que respondam a questóes de seus interesses.

Exemplos de aplicação do referencial teórico de ignorância na análise de problemas de políticas públicas podem ser encontrados em Ravetz (1987), que discute a formulaçáo de políticas públicas no contexto de "ciência incompleta"; em Gaudet (2015), que apresenta um modelo conceitual do processo de mobilização de ignorância e evidências nas políticas públicas; e no estudo de Rayner (2015) sobre o uso retórico de ignorância nos debates sobre geoengenharia para controle do aquecimento global. Adicionalmente, Dedieu, Jouzel e Prete (2015) investigam os mecanismos de produçáo institucional de ignorância a respeito do envenenamento de trabalhadores rurais por pesticidas, no contexto da regulação ambiental; e, de modo semelhante, McGoey (2007) analisa o caso da regulação dos antidepressivos Prozac e Seroxat, argumentando haver um certo "desejo por ignorância” nas burocracias regulatórias, a fim de se manter uma imagem de coerência e credibilidade.

Tal qual a diversidade de disciplinas engajadas nos estudos sobre ignorância, também são múltiplas as abordagens investigativas. Para esse trabalho, optou-se por uma estratégia de abordagem interpretativa delineada por Smithson (2015), em que se busca compreender as perspectivas dos agentes sobre o que é ignorância, a quem é atribuída, como respondem e que uso fazem, além de mapear se há consenso ou divergência sobre os critérios de aceitação de um conhecimento como verdadeiro.

\section{ANÁLISE DOS DADOS EMPÍRICOS}

Nesta seção, apresenta-se a análise de conteúdo de seis votos de diretores da Anvisa, produzidos ao longo do processo deliberativo sobre as propostas de regulação dos requisitos técnicos e administrativos para cultivo de cannabis para fins medicinais ou científicos e de regulamento específico para registro de medicamentos à base de cannabis, entre junho e dezembro de 2019.

Trata-se de uma abordagem interpretativa, ou seja, interessa identificar a perspectiva do autor sobre se, em dado tópico, há (ou não há) ausência de conhecimento. Não é incomum que ignorâncias percebidas por um indivíduo sejam construídas como conhecimento por outro indivíduo ou em outro momento. 
QUADRO 3

Documentos analisados

\begin{tabular}{|c|l|l|l|}
\hline \multicolumn{1}{|c|}{ Data } & \multicolumn{1}{|c|}{ Voto } & \multicolumn{1}{c|}{ Diretor } & \multicolumn{1}{c|}{ Posicionamento } \\
\hline $11 / 6 / 2019$ & Voto no 14/2019/Quinta Diretoria/Anvisa/2019 & William Dib & $\begin{array}{l}\text { Vota pela abertura de consultas } \\
\text { públicas sobre ambas as propostas }\end{array}$ \\
\hline $11 / 6 / 2019$ & Voto no 54/2019/Quarta Diretoria/Anvisa/2019 & William Dib & $\begin{array}{l}\text { Vota pela abertura de consultas } \\
\text { públicas sobre ambas as propostas }\end{array}$ \\
\hline $16 / 10 / 2019$ & Voto no 25/Primeira Diretoria/Anvisa/2019 & Antonio Barra Torres & $\begin{array}{l}\text { Vota pela aprovação de ambas } \\
\text { as propostas }\end{array}$ \\
\hline $3 / 12 / 2019$ & Voto no 39/Quinta Diretoria/Anvisa/2019 & Velativa ao cultiva \\
\hline $3 / 12 / 2019$ & Voto no 92/2019/Quarta Droposta \\
\hline $3 / 12 / 2019$ & Voto no 96/2019/Quarta Diretoria/Anvisa/2019 & Fernando Mendes Garcia Neto & $\begin{array}{l}\text { Vota pela aprovação da } \\
\text { proposta relativa ao registro } \\
\text { de medicamentos }\end{array}$ \\
\hline
\end{tabular}

Elaboração da autora.

Por essa razão, a análise foi feita em duas etapas. Primeiramente, buscou-se mapear quais ignorâncias (ausência de conhecimento) foram mobilizadas e para qual finalidade na construção do argumento e posicionamento do voto, momento em que foram identificadas seis "ignorâncias" relevantes para a deliberação. Em seguida, buscou-se identificar se as questóes postas como ignorância em um voto foram consideradas conhecidas nos demais.

QUADRO 4

Questões construídas como ignorância e suas abordagens nos votos

\begin{tabular}{|c|c|c|c|c|c|c|}
\hline Questões & Voto no 14 & Voto no 54 & Voto $n^{\circ} 25$ & Voto no 39 & Voto $n=92$ & Voto no 96 \\
\hline 1) A cannabis apresenta propriedades terapêuticas? & $\operatorname{lgn}$. & Ign. & $\operatorname{lgn}$. & Ign. & Ign. & Ign. \\
\hline $\begin{array}{l}\text { 2) Os produtos importados à base de cannabis apresentam } \\
\text { segurança, eficácia e qualidade? }\end{array}$ & Ign. & - & Ign. & - & Ign. & - \\
\hline 3) A Anvisa tem competência para regular o plantio? & Conh. & Ign. & Conh. & Ign. & - & - \\
\hline $\begin{array}{l}\text { 4) A regulação do plantio reduzirá o custo dos medicamentos à } \\
\text { base de cannabis? }\end{array}$ & - & - & Conh. & $\operatorname{lgn}$. & - & Ign. \\
\hline $\begin{array}{l}\text { 5) Quais serão os impactos da regulação do plantio em outros } \\
\text { setores de políticas públicas? }\end{array}$ & - & $\operatorname{lgn}$. & Conh. & Ign. & - & Ign. \\
\hline $\begin{array}{l}\text { 6) Há capacidade técnica e institucional dos órgãos governamentais } \\
\text { envolvidos no controle e na fiscalização do plantio? }\end{array}$ & - & Ign. & - & Ign. & - & Ign. \\
\hline
\end{tabular}

Elaboração da autora.

\section{1) A cannabis apresenta propriedades terapêuticas?}

Essa questão foi reconhecida como ignorância em todos os votos. Entretanto, os posicionamentos divergiram. Nos votos $\mathrm{n}^{-} 14$ e $\mathrm{n}^{-} \mathbf{2 5}$, o diretor William Dib identifica as causas dessa lacuna de conhecimento em preconceitos e equívocos históricos que levaram à indisponibilidade e ilegalidade da planta, para enfatizar a necessidade de avançar na regulamentação do cultivo, nestes termos:

Entendendo que: sem a planta - não há insumo. Sem insumo não há medicamento. De mesma sorte que: sem insumo não há pesquisa. Sem pesquisa não há avanço para determinar o potencial terapêutico exato e tampouco para usufruir do que dele já se conhece. Sem a determinação exata, se corrobora 
para que o desconhecimento seja o território para o manejo de condiçóes de saúde - permissão que não prospera na missão e na razão de ser dessa agência (Anvisa, 2019c, voto no 25, p. 8).

Em contraponto, o voto $\mathrm{n}^{\mathrm{0}}$ 39, do diretor Antonio Barra, mobiliza a existência dessa ignorância como indicativo de que o assunto não foi suficientemente debatido com outros órgáos governamentais e, portanto, a proposta de regulação do plantio deve ser rejeitada e arquivada. Evidencia que persistem preocupações acerca da insuficiência de evidências científicas sobre os efeitos terapêuticos da cannabis e da possibilidade de manipulação das evidências por interesses econômicos e políticos, a exemplo de manifestação do Ministério da Educação de que interesses econômicos "desafiam cientistas, governos e comunidade" (Anvisa, 2019d, voto no 39, p. 35); e da Polícia Federal, de que "grandes interesses econômicos e políticos se valem de possíveis, e às vezes fantasiosos, efeitos medicinais da cannabis spp. para embasar campanhas de legalização irrestrita de uso", apontando o risco de que a regulamentação do plantio incentive a "realização de pesquisas de motivação e metodologia duvidosas, para produzir resultados encomendados sobre supostos efeitos benéficos da maconha, afetando prejudicialmente as crenças normativas acerca do abuso da droga” (Anvisa, 2019d, voto no 39, p. 31).

Por outro lado, nos votos n⿳⺈ 54, 92 e 96, o diretor Fernando Mendes reconhece a existência de ignorância sobre o potencial terapêutico, mas, diferentemente do diretor William Dib, não entende que a superação dessa ignorância perpassa a regulamentação do plantio em solo nacional, uma vez que "a cannabis e seus derivados a serem utilizados na fabricação de medicamentos ou outros produtos não" precisariam necessariamente ser obtidos "de plantaçóes em terras brasileiras" (Anvisa, 2019e, voto no 92, p. 1). Ao reconhecer a existência de ignorância científica sobre as propriedades terapêuticas da cannabis, o faz em contraste à existência de evidência não científica constituída de relatos de melhora clínica de milhares de pacientes. Argumenta que, em razão dessa ignorância, há necessidade de flexibilização das regras de registro de medicamentos à base de cannabis para disponibilização no mercado antes da conclusão dos estudos sobre eficácia e segurança. Desse modo, busca dar legitimidade aos "doentes desesperados postos espontaneamente em condiçóes de cobaia, porque entendem não haver nada mais negativo que seu sofrimento" (Anvisa, 2019e, voto $\mathrm{n}^{-}$92, p. 4), caso em que "o Estado gestor, regulador, acusador (...) não pode exigir dessas pessoas comportamento diverso, ao contrário, deve ele agir para conformar a situação fática, amoldando suas regras para legitimar esse comportamento" (Anvisa, 2019e, voto no 92, p. 4).

\section{2) Os produtos importados à base de cannabis apresentam segurança, eficácia e qualidade?}

Essa questão foi relevante para a aprovação do regulamento específico para registro de medicamentos à base de cannabis, tema abordado nos votos nos 14 e 25 (William Dib) e no 92 (Fernando Mendes). Em todos os votos, adotou-se o mesmo posicionamento: reconhecer a ignorância sobre a eficácia, a segurança e a qualidade dos produtos importados, e, na impossibilidade imediata de atestar-se eficácia e segurança (por limitação do conhecimento científico), propor uma via alternativa de registro de medicamentos que garanta ao menos a qualidade em um primeiro momento. Particularmente, quanto à questão da qualidade, no voto $\mathrm{n}$ o 25 apresenta-se evidência (e, portanto, conhecimento) de que grande parte dos produtos importados não possuem qualidade, conforme estudo produzido pela Universidade Federal do Rio de Janeiro (UFRJ) que demonstra haver discrepância entre rótulo e conteúdo de $\mathrm{CBD}$, além de contaminação por metais pesados, pesticidas, solventes tóxicos e THC acima do recomendado. Portanto, a comprovaçáo de falta de qualidade, somada à ignorância científica sobre eficácia e segurança, deram respaldo à aprovação de regra específica para registro de 
medicamentos à base de cannabis. Autoriza-se provisoriamente a comercialização de produtos com estudos em andamento pelo prazo improrrogável de cinco anos, desde que atendidos os requisitos de qualidade. Nesse prazo, a empresa deverá apresentar os estudos que comprovem segurança e eficácia para registro definitivo como medicamento.

Portanto, vendo-se diante de uma "circunstância fática absolutamente sedimentada e irreversível" (Anvisa, 2019e, voto no 92, p. 9), em que "mais de 13 mil unidades, já importadas, representam, hoje, o arrepio ao farto e amplo conjunto normativo que" a Anvisa "tem produzido no sentido de delimitar - por meio do conhecimento que o mundo tem produzido ao longo dos séculos - quais as melhores condiçóes técnicas de produção, quais os melhores parâmetros de segurança para uma formulação e por fim, quais as indicaçóes e os efeitos esperados” (Anvisa, 2019c, voto no 25, p. 7-8), a flexibilização das regras de registro para medicamentos à base de cannabis indica a aceitação do risco representado pela ignorância da eficácia e segurança, como forma de dirimir a ignorância sobre a qualidade.

\section{3) A Anvisa tem competência para regular o plantio?}

Esta questáo, de natureza formal, foi objeto de divergências e determinante para a rejeiçáo da proposta de regulaçáo do cultivo. Nos votos n ${ }^{\text {os }} 14$ e 25 , o diretor William Dib alega conhecimento sobre a competência da Anvisa para regular o plantio de cannabis, baseando-se em dispositivos legais e regulamentares. Em contraposição, o diretor Fernando Mendes, em seu voto n⿳0 54, parece hesitar sobre o assunto, ao empregar a expressáo "independentemente da nossa competência legal" (Anvisa, 2019a, voto $\mathrm{n}^{-} 54$, p. 1) para fundamentar a abertura de discussão pública sobre o assunto. Por fim, no voto $\mathrm{n}^{\mathrm{o}}$ 39, o diretor Antonio Barra indica dúvidas sobre a competência como fundamento para rejeição e arquivamento da proposta: apesar de haver manifestação da Procuradoria Federal da Anvisa atestando a competência legal nessa matéria, a Diretoria Colegiada da Anvisa e o Ministério da Saúde manifestaram-se em sentido contrário, e não há parecer harmonizador da Advocacia-Geral da União (AGU).

\section{4) A regulação do plantio reduzirá o custo dos medicamentos à base de cannabis?}

Esta questão é um exemplo de discordância quanto aos critérios de aceitação do que é conhecimento. Um fato que, na perspectiva de um dos diretores, seria um conhecimento evidente por razóes lógicas, para os outros dependeria de comprovação por evidências científicas. Inicialmente, no voto no 25 , William Dib alegou conhecimento de que a regulação do plantio contribuiria para redução do custo, um raciocínio que decorre logicamente do pressuposto de que a ilegalidade e a indisponibilidade da planta são a raiz tanto da escassez de evidências científicas quanto do alto custo dos medicamentos. Nesse sentido, posiciona-se pela regulação do plantio como forma de reduzir os custos para o consumidor e para o Sistema Único de Saúde (SUS). Por seu turno, nos votos no 39 (Antonio Barra) e no 96 (Fernando Mendes), enfatiza-se a ignorância sobre a questão, devido à ausência de estudo econômico que comprove essa relação de causalidade, fundamentando-se assim a decisão de rejeitar e arquivar a proposta.

\section{5) Quais serão os impactos da regulação do plantio em outros setores de políticas públicas?}

Esta questão foi posta inicialmente como ignorância no voto no 54 , de Fernando Mendes, que aprova a consulta pública, indicando o potencial impacto na segurança pública como fundamento 
da necessidade de estreitar o diálogo com os órgãos correlatos. Na sequência, em seu voto no 25 , William Dib argumenta haver conhecimento sobre os impactos na segurança pública e assevera que estes foram levados em consideração na formulação da proposta de regulação, estando esta, portanto, em condiçóes de ser aprovada. Em oposição, nos votos no 39 (Antonio Barra) e no 96 (Fernando Mendes), argumenta-se que os impactos multissetoriais não foram levados em consideraçáo, ampliando o escopo de potenciais impactos para além da segurança pública - agricultura, defesa da concorrência, saúde pública -, com diversas questôes que permanecem náo respondidas pelo incipiente diálogo com outros órgãos governamentais.

6) Há capacidade técnica e institucional dos órgãos governamentais envolvidos no controle e fiscalização do plantio?

$\mathrm{O}$ argumento de ignorância quanto à capacidade para controle e fiscalização esteve atrelado à questão anterior (ignorância sobre os impactos em outros setores). Esta questão foi apontada como ignorância nos votos $\mathrm{n}^{\mathrm{os}} 54$, 39 e 96. Inicialmente, no voto $\mathrm{n}^{\mathrm{0}}$ 54, a ignorância foi mobilizada para fundamentar a necessidade de diálogo com outros órgáos. Por sua vez, nos votos nos 39 e 96 , afirma-se que a questáo não foi avaliada a contento, permanecendo a ignorância sobre os impactos de custo e carga administrativa, além do insuficiente envolvimento de órgãos a quem se atribuem responsabilidades, o que fundamentaria o posicionamento de rejeição da proposta.

\section{CONCLUSÃO}

A abordagem interpretativa para mapeamento das ignorâncias mostrou-se uma ferramenta útil e relevante na compreensão do desenrolar recente de regulação da cannabis medicinal no Brasil. Com relação à aprovação da regulaçáo que flexibilizou as regras para registro de medicamentos à base de cannabis, baseou-se primordialmente na ignorância sobre a eficácia, segurança e qualidade dos produtos importados. A resposta a essa ignorância consistiu em autorizar a comercialização de produtos à base de cannabis antes da conclusão dos estudos sobre eficácia e segurança, de forma provisória, até que se concluam os estudos. Desse modo, busca-se uma solução de curto prazo para dirimir as incertezas sobre a qualidade, ao mesmo tempo que se aceita o risco de comercializaçáa de produtos que podem, no futuro, provar-se ineficazes e inseguros.

Por outro lado, quanto à rejeição da regulação do cultivo em solo brasileiro, deve-se em grande parte à percepção de incerteza sobre os impactos em outros setores de políticas públicas e acerca da ausência de conhecimento sobre a capacidade de controle e fiscalização. Ademais, a proposição de que o plantio em solo nacional propiciaria redução de custos do medicamento não foi aceita como verdadeira pelo conjunto de diretores, que consideraram haver ignorância nesse quesito, devido à ausência de estudo econômico que demonstrasse a causalidade. Adicionalmente, prevaleceu a perspectiva de ignorância sobre as competências formais da Anvisa. Por fim, embora tenha havido consenso quanto à existência de ignorância sobre as propriedades terapêuticas, prevaleceu o posicionamento de que a regulação do plantio não é medida necessária à superação dessa ignorância.

O tema da regulação do cultivo continua em aberto. Independentemente do vácuo regulatório de critérios técnicos para cultivo, na prática já existem plantações de cannabis para uso próprio no país, por salvaguarda judicial. Algumas famílias têm obtido na Justiça o direito de plantar cannabis para uso próprio individual desde 2016 (Cancian e Collucci, 2019). Como exemplo, a Associação Brasileira de Apoio Cannabis Esperança (Abrace) foi autorizada a plantar cannabis para atender 
aos seus 151 associados, por decisão da Justiça Federal da Paraíba de abril de 2017. ${ }^{9}$ Além disso, a questão do plantio ainda está por ser apreciada pelo Supremo Tribunal Federal (STF) na Ação Direta de Inconstitucionalidade (ADI) nำ 5.708.

É recomendável, para uma boa prática regulatória, que o debate sobre regulação do plantio de cannabis prossiga na esfera técnico-administrativa, antes que a Anvisa seja atropelada, mais uma vez, por determinaçóes judiciais. Tratando-se de um tema complexo e multissetorial, as consequências imprevistas podem ser mitigadas, a partir do mapeamento dos pontos de ignorância relevantes e da reflexão sobre quais ignorâncias são superáveis, bem como da pactuaçáo de critérios para aceitação de conhecimento como válido. Nesse posicionamento está a diferença entre instrumentalizar a ignorância para pôr fim a um debate controverso, ou instrumentalizar a ignorância como propulsora de conhecimento.

Por fim, a análise das decisões da Anvisa sobre regulação de cannabis para usos medicinais sinaliza a necessidade de ampliação dos critérios pelos quais se avalia a legitimidade de atuação das agências reguladoras. Para além da atenção à utilização de conhecimento técnico-científico e mobilização de evidências, também a razoabilidade das alegaçôes de ignorância e seus usos como fundamento decisório devem ser objeto de análise pela sociedade.

\section{REFERÊNCIAS}

ANVISA - AGÊNCIA NACIONAL DE VIGILÂNCIA SANITÁRIA. Voto nº 54/2019/Quarta Diretoria/Anvisa/2019/SEI/DIRE4/Anvisa - Propostas de consulta pública que dispóe sobre os requisitos técnicos e administrativos para o cultivo da planta Cannabis spp. para fins medicinais e científicos e dá outras providências. Relator Fernando Mendes Garcia Neto, 11 de junho de 2019a.

. Voto nº 14/2019/Quinta Diretoria/Anvisa/2019/SEI/DIRE5/Anvisa. Relator William Dib, 12 de junho de 2019b.

- Voto no 25/DIRE1/Anvisa/2019/SEI/DIRE1/Anvisa - Proposta de Resolução de Diretoria Colegiada - RDC que dispóe sobre os requisitos técnicos e administrativos para o cultivo da planta Cannabis spp. exclusivamente para fins medicinais ou científicos, e dá outras providências. Relator William Dib, 16 de outubro de 2019c.

- Voto no 39/2019/SEI/DIRE5/Anvisa - Assunto: Retorno de vista de Proposta de Resolução de Diretoria Colegiada - RDC que dispóe sobre os requisitos técnicos e administrativos para o cultivo da planta Cannabis spp. exclusivamente para fins medicinais ou científicos, e dá outras providências. Diretor Antonio Barra Torres, 3 de dezembro de 2019d.

. Voto no 92/2019/Quarta Diretoria/Anvisa/2019/SEI/DIRE4/Anvisa - Retorno de vista relativamente à proposta de RDC que dispóe sobre procedimento para registro e monitoramento de medicamentos à base de Cannabis spp., seus derivados e análogos sintéticos. Relator Fernando Mendes Garcia Neto, 3 de dezembro de 2019e. 
. Voto no 96/2019/Quarta Diretoria/Anvisa/2019/SEI/DIRE4/Anvisa - Relativo à proposta de RDC que dispóe sobre os requisitos técnicos e administrativos para o cultivo da planta Cannabis spp. exclusivamente para fins medicinais ou científicos, e dá outras providências. Relator Fernando Mendes Garcia Neto, 3 de dezembro de $2019 f$.

BERRIDGE, V. Demons: our changing attitudes to alcohol, tobacco, and drugs. Oxford: Oxford University Press, 2013.

CANCIAN, N.; COLLUCCI, C. Proposta da Anvisa para plantio de maconha tem resistência dentro da própria agência. Folha de S.Paulo, 1o out. 2019. Disponível em: <https://www1.folha.uol.com. br/equilibrioesaude/2019/10/proposta-da-anvisa-para-plantio-de-maconha-tem-resistencia-dentroda-propria-agencia.shtml>. Acesso em: 11 out. 2019.

DEDIEU, F; JOUZEL, J.; PRETE, G. Governing by ignoring: the production and the function of the under-reporting of farm-workers' pesticide poisoning in French and Californian regulations. In: GROSS, M.; MCGOEY, L. (Ed.). Routledge international handbook of ignorance studies. Abingdon: Routledge, 2015. p. 297-307.

DESMARAIS, B. A.; HIRD, J. A. Public policy's bibliography: the use of research in US regulatory impact analysis. Regulation and Governance, v. 8, n. 4, p. 497-510, 2014.

GAUDET, J. Unfolding the map: making knowledge and ignorance mobilization dynamics visible in science evaluation and policymaking. In: GROSS, M.; MCGOEY, L. (Ed.). Routledge international handbook of ignorance studies. Abingdon: Routledge, 2015. p. 318-327.

HESS, D. J. Undone science and social movements: a review and typology. In: GROSS, M.; MCGOEY, L. (Ed.). Routledge international handbook of ignorance studies. Abingdon: Routledge, 2015. p. $141-154$.

KEMPNER, J. The production of forbidden knowledge. In: GROSS, M.; MCGOEY, L. (Ed.). Routledge international handbook of ignorance studies. Abingdon: Routledge, 2015. p. 77-83.

KERWIN, A. None too solid: medical ignorance. Science Communication, v. 15, n. 2, p. 166-185, 1993.

MCCALL, C. Momentum grows for medical use of cannabis. The Lancet, v. 386, p. 1.615-1.616, 2015. Disponível em: <https://doi.org/10.1016/S0140-6736(15)00674-1>.

MCGOEY, L. On the will to ignorance in bureaucracy. Economy and Society, v. 36, n. 2, p. 212-235, 2007.

Strategic unknowns: towards a sociology of ignorance. Economy and Society, v. 41, n. 1, p. 1-16, 2012.

MILLS, J. H. Science, diplomacy and cannabis: the evidence base and the international drugs regulatory system 1924-1961. In: COLLINS, J. (Ed.). Governing the global drug wars. Londres: LSE, 2012. p. 25-30.

NUTT, D. J.; KING, L. A.; NICHOLS, D. E. Effects of schedule I drug laws on neuroscience research and treatment innovation. Nature Reviews Neuroscience, v. 14, p. 577-585, 2013. 
OLIVEIRA, F. S. R. Maconheirinhos: cuidado, solidariedade e ativismo de pacientes e seus familiares em torno do óleo de maconha rico em canabidiol (CBD). 2016. Dissertaçáo (Mestrado) Universidade de Brasília, Brasília, 2016.

OMS - ORGANIZAÇÃO MUNDIAL DA SAÚDE. Third session of the World Health Organization Expert Committee on drug liable to produce addiction. Genebra: United Nations Office on Drugs and Crime, 1952. Disponível em: <http://www.unodc.org/unodc/en/data-andanalysis/bulletin/bulletin_1952-01-01_3_page008.html>. Acesso em: 5 maio 2020.

PINTO, M. F. Tensions in agnotology: normativity in the studies of commercially driven ignorance. Social Studies of Science, v. 45, n. 2, p. 294-315, 2015.

RAVETZ, J. R. Usable knowledge, usable ignorance: incomplete science with policy implications. Knowledge: Creation, Diffusion, Utilization, v. 9, n. 1, p. 87-116, 1987.

RAYNER, S. To know or not to know? A note on ignorance as a rhetorical resource in geoengineering debates. In: GROSS, M.; MCGOEY, L. (Ed.). Routledge international handbook of ignorance studies. Abingdon: Routledge, 2015. p. 308-317.

ROBERTS, J. Organizational ignorance. In: GROSS, M.; MCGOEY, L. (Ed.). Routledge international handbook of ignorance studies. Abingdon: Routledge, 2015. p. 361-369.

SCHIEBINGER, L. Agnotology and exotic abortifacients: the cultural production of ignorance in the eighteenth-century Atlantic world. Proceedings of the American Philosophical Society, v. 149, n. 3, p. 316-343, 2005.

SMITHSON, M. Afterword: ignorance studies - interdisciplinary, multidisciplinary, and transdisciplinary. In: GROSS, M.; MCGOEY, L. (Ed.). Routledge international handbook of ignorance studies. Abingdon: Routledge, 2015. p. 385-399.

WAGNER, W. E. The "bad science" fiction: reclaiming the debate over the role of science in public health and environmental regulation. Law and Contemporary Problems, v. 63, n. 4, p. 63-132, 2003. 